\title{
Correlation between subgrains and coherently scattering domains
}

\author{
T. Ungár ${ }^{a)}$ \\ Department of General Physics, Eötvös University, Pázmány Péter sétány 1A, \\ Budapest H-1518 POB 32, Hungary \\ G. Tichy and J. Gubicza \\ Department of Solid State Physics, Eötvös University, Pázmány Péter sétány 1A, \\ Budapest H-1518 POB 32, Hungary \\ R. J. Hellmig \\ Institut für Werkstoffkunde und Werkstofftechnik, TU Clausthal, Agricolastr, 6, \\ 38678 Clausthal-Zellerfeld, Germany
}

(Received 8 July 2005; accepted 12 October 2005)

\begin{abstract}
Crystallite size determined by X-ray line profile analysis is often smaller than the grain or subgrain size obtained by transmission electron microscopy, especially when the material has been produced by plastic deformation. It is shown that besides differences in orientation between grains or subgrains, dipolar dislocation walls without differences in orientation also break down coherency of $\mathrm{X}$-rays scattering. This means that the coherently scattering domain size provided by X-ray line profile analysis provides subgrain or cell size bounded by dislocation boundaries or dipolar walls. (C) 2005 International Centre for Diffraction Data. [DOI: 10.1154/1.2135313]
\end{abstract}

Key words: X-ray line profile analysis, transmission electron microscopy (TEM), crystallite size, subgrains, dipolar dislocation walls

\section{INTRODUCTION}

According to the kinematical theory of powder diffraction if the crystallites (coherently scattering domains) are strain-free and the average crystallite size is larger than a few microns, however, not much larger than about $10 \mu \mathrm{m}$, the physical line profiles of the diffraction peaks are delta functions (Warren, 1990). In a polycrystalline structural material or in a realistic powder specimen several deviations from the ideal state can be present: (1) internal stresses, (2) stacking faults, (3) twinning, (4) crystallite smallness, (5) microstresses, (6) long-range internal stresses, (7) chemical heterogeneities, (8) anisotropic crystallite shape, or (9) anisotropic strain, etc. All these features and often their combinations comprise the microstructure of an investigated specimen. The presence of different microstructural features is manifested by different specific distortions of the ideal powder diffraction pattern. (i) Peak shift is related to internal stresses or planar faults, especially stacking faults or twinning. (ii) Peak broadening indicates crystallite smallness and microstresses, however, stress gradients and/or chemical heterogeneities can also cause peak broadening. (iii) Peak asymmetries can be caused by long-range internal stresses (in particular gradients), planar faults or chemical heterogeneities. (iv) Anisotropic peak broadening can result from anisotropic crystallite shape or anisotropic strain. Here the anisotropic broadening means that the peak breadth is a nonmonotonous function of the momentum of the diffraction vector. There is no one-to-one correlation between the different peak profile features and the different microstructural properties. The interpretation of shape of peak profiles in terms of microstructural properties becomes more reliable if the results of other methods, e.g., transmission or scanning electron microscopy (TEM or SEM), are also used. On the

${ }^{a)}$ Electronic mail: ungar@ludens.elte.hu other hand, the results of other methods, especially TEM or SEM, can be refined and/or amended by using X-ray line profile analysis (XLPA).

The different microstructural properties from (1) to (9) can be treated on a well-established physical basis. Internal stresses are described by the elastic properties of crystals (Macherauch, 1980; Noyan and Cohen, 1987). Methods for the determination of probabilities of stacking faults and twinning from diffraction profiles have been elaborated for cubic and hexagonal crystals by Warren (1990), Treacy et al. (1991), Scardi and Leoni (1999), Boulle et al. (2001), Estevez-Rams et al. (2003), and Ustinov et al. (2004). Size broadening has been treated for spherical or nonspherical crystallites (Le Bail and Louër, 1978; Louër et al., 1983; Langford et al., 1993; van Berkum et al., 1994; Langford et al., 2000; Leoni and Scardi, 2004; Ungár et al., 2001; Audebrand et al., 2003; Ida et al., 2003). The evaluation of microstresses has been worked out in detail for dislocations (Krivoglaz, 1996; Wilkens, 1970; Gaál, 1984; Groma et al., 1988, Ungár and Borbély, 1996; Levine and Thomson, 1997; Groma, 1998). Long-range internal stresses were related to the dipole polarization of dislocations (Mughrabi, 1983; Mughrabi et al., 1986, Groma et al., 1988). Anisotropic crystallite shape has been treated by Louër et al. (1983) in the case of $\mathrm{ZnO}$ nanoparticles. Anisotropic peak broadening caused by strain is a general phenomenon which is closely related to the elastic properties of crystals and/or the anisotropic strain field of dislocations (Ungár and Borbély, 1996; Ungár and Tichy, 1999; Scardi and Leoni, 1999; Dinnebier et al., 1999, Stephens, 1999; Cheary et al., 2000).

One of the most frequent applications of XLPA is the determination of size or size distribution of crystallites. According to the theorem of Bertaut (1950) the profile of a size broadened peak can be obtained as the sum of the intensities diffracted by parallel and independent columns which build up the diffracting crystallites and aligned normal to the re- 
flecting planes with unit cross-sectional area. The diffraction peak corresponding to one particular column is the squared Fourier transform of the form function pertaining to that column length. The final size-broadened peak is the volumeweighted sum of the individual peaks corresponding to the individual columns. The direct meaning of a size broadened peak is thus related to the (area and/or volume) weighted column-length distribution in the specimen. The columnlength distribution in the specimen depends on the size, the shape, and the size distribution of the crystallites. In order to obtain the (area and/or volume weighted) mean size of crystallites or their distributions, specific assumptions have to be made about the shape and the size distribution of these objects (Langford and Louër, 1996).

There is ample experimental evidence that the lognormal size distribution function, $f(x)$, given by the median $m$ and the variance $\sigma$, can describe crystallite size distribution in a wide range of bulk or loose powder materials (Valiev et al., 1994; Terwilliger and Chiang, 1995; Krill and Birringer, 1998; Ungár et al., 1999; Langford et al., 2000; Scardi and Leoni, 2002). Hinds (1982) has shown that with $m$ and $\sigma$ the arithmetic-, the area-, and the volume-weighted mean crystallite diameters are

$$
\langle x\rangle_{j}=m \exp \left(k \sigma^{2}\right)
$$

where $k=0.5,2.5$, and 3.5 in the case of arithmetic-, area-, and volume-weighted mean and $j$ stands for these different averages, respectively.

Crystallite size, grain size, or particle size are microstructural features which can be determined and even visualized by electron microscopy methods, e.g., TEM or SEM, and can also be determined by other methods, e.g., specific surface area measurement by Brunauer-Emmet-Teller (BET) procedure. In the present paper, size values provided by these methods are discussed in terms of the size values given by XLPA. It will be shown that when strain is caused either by dislocations or by other defects producing inhomogeneous strain, e.g., contact stresses between adjacent particles or triple junctions between three grain boundaries, crystallographic misorientation between the adjacent objects is not a prerequisite for breaking down coherency. Especially, in the case of dipolar dislocation walls it will be shown that, though the adjacent regions follow exactly the same crystallographic orientation, coherency is lost in most crystallographic directions.

\section{THE CORRELATION BETWEEN CRYSTALLITE SIZE OR SIZE-DISTRIBUTIONS AS DETERMINED EITHER BY X-RAY LINE PROFILE ANALYSIS (XLPA) OR BY TRANSMISSION ELECTRON MICROSCOPY (TEM)}

In the following some representative experimental results are reviewed where crystallite size has been determined by both the methods of XLPA and electron microscopy. These results are discussed within the two categories: (1) when X-ray and TEM sizes are in good agreement, and (2) when X-ray and TEM sizes show discrepancies.

\section{A. When X-ray and TEM sizes are in good agreement}

It has been shown in numerous papers that in nanostructured ceramic powders the crystallite size and the grain size values determined by XLPA and TEM, respectively, agree well within the experimental error (Louër et al., 1983; Langford et al., 1993; Langford et al., 2000; Gubicza et al., 2000a). For example Louër and co-workers have prepared loose powder of $\mathrm{ZnO}$ by the thermal decomposition of zinchydroxinitrate, $\mathrm{Zn}_{3}(\mathrm{OH})_{4}\left(\mathrm{NO}_{3}\right)_{2}$ (Louër et al., 1983). In order to avoid secondary growth after the first decomposition from the precursors the ambient conditions were carefully controlled. The TEM image obtained on $\mathrm{ZnO}$ powder shows well-defined cylindrical nanoparticles with aspect ratios of about 3. The Williamson-Hall plot of the full width at half maximum (FWHM) of the diffraction profiles revealed a strong anisotropy with the indices of reflections $h k l$, however, with clear indication for the absence of strain, e.g., FWHM values of the 002/004 and 100/300 pairs of reflections are identical within the experimental error in the reciprocal lattice scale. Based on this behaviour of the Williamson-Hall plot, authors evaluated the shape anisotropy in terms of a cylindrical particle model. The average cylinder diameter and height was obtained as 8 and $20 \mathrm{~nm}$, respectively, in excellent agreement with the TEM results.

Langford and co-workers have studied the effect of size distribution on X-ray powder diffraction peak profiles (Langford et al., 2000). Nanocrystalline powder specimens of $\mathrm{CeO}_{2}$ were prepared from the decomposition of an oxidenitrate, $\mathrm{Ce}_{2} \mathrm{O}\left(\mathrm{NO}_{3}\right)_{6} \cdot \mathrm{H}_{2} \mathrm{O}$, under $\mathrm{N}_{2}$ atmosphere with a heating rate of $3 \mathrm{~K} / \mathrm{h}$ up to $503 \mathrm{~K}$. The specimen was additionally annealed for $24 \mathrm{~h}$ at the same temperature. The high resolution TEM (HREM) micrograph (see Figure 3, in Langford et al., 2000) has shown crystallites of the diameter of about $4 \mathrm{~nm}$. Assuming log-normal size distribution the diffraction patterns were fitted by a Rietveld type whole powder pattern fitting procedure. The size distribution provided by the fitting procedure is in perfect agreement with the bar diagram obtained by evaluating the TEM micrographs (Langford et al., 2000; Scardi et al., 2004; Balzar et al., 2004).

The crystallite size distribution in nanocrystalline silicon nitride ceramic loose powders has also been investigated by XLPA methods (Gubicza et al., 2000a; Gubicza et al., 2000b). Two methods were used to produce $\mathrm{Si}_{3} \mathrm{~N}_{4}$ powders. One of the two procedures was the gas-phase synthesis of silicon-tetrachloride and ammonia in thermal plasma reactor (Gubicza et al., 2000b). The majority (80 vol \%) of the assynthesized powder was amorphous. This powder was crystallized at $1500{ }^{\circ} \mathrm{C}$ for $2 \mathrm{~h}$. After the crystallization heattreatment an amorphous fraction of about $20 \%$ is still retained. Another powder was formed by nitridation of silicon and subsequent milling. The latter specimen was fully crystalline. Both powders were studied by XLPA and TEM. A TEM image for the powder crystallized at $1500{ }^{\circ} \mathrm{C}$ is shown in Figure 1. The grain size distribution obtained by TEM and the crystallite size distribution determined by XLPA are compared in Figure 2. The X-ray line profiles were evaluated by the Multiple Whole Profile (MWP) fitting method (Ungár et al., 2001). A large number of TEM micrographs were evaluated for grain size. About 300 grains were chosen at random in different areas in different micrographs. 


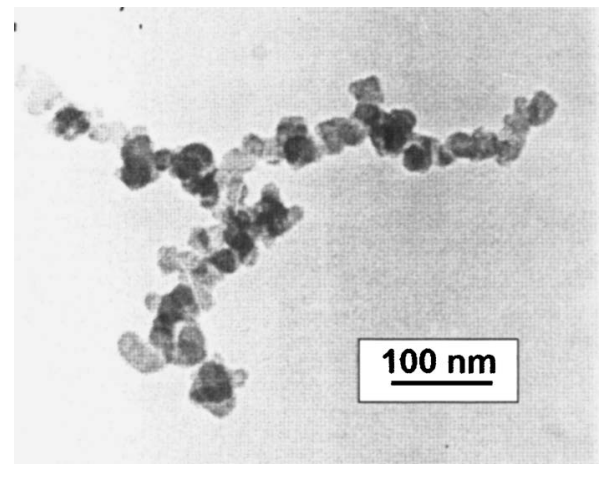

Figure 1. TEM micrograph of silicon nitride ceramic powder synthesized in thermal plasma and crystallized at $1500{ }^{\circ} \mathrm{C}$.

The frequency of the measured diameters is shown in Figure 2 as bar graphs. The solid line in the figure is the size distribution function obtained by XLPA. The agreement between the size distributions obtained by TEM and X-rays is relatively good. The difference between the two distributions can be attributed to the smallest amorphous grains in the powder specimen (Gubicza et al., 2000b). Another reason is that the number of grains sampled in the present X-ray diffraction experiments is many orders of magnitude larger than the number evaluated in the TEM experiments. Similar comparison of the crystallite size distributions has been made for the nanodisperse $\mathrm{Si}_{3} \mathrm{~N}_{4}$ powder formed by nitridation of silicon and subsequent milling. For this fully crystalline sample the agreement between the X-ray and TEM size distributions was better than for the powder obtained by thermal plasma synthesis. The area weighted mean crystallite size obtained from XLPA was compared with that calculated from the specific surface area determined by Brunauer-Emmett-Teller (BET) method (Gubicza et al., 2000a). For both powders the area weighted mean size obtained from XLPA (93 and $62 \mathrm{~nm}$ for the plasma and nitridized powders, respectively) were in good agreement with those determined by BET method (94 and $71 \mathrm{~nm}$ for the plasma and nitrided powders, respectively, assuming spherical particles).

The relatively good correlation between the crystallite size determined by XLPA and the grain size obtained by TEM has also been shown for not only ceramic powders but also nanostructured metallic materials formed by electrodeposition, inert-gas condensation, or crystallization from amorphous precursors. For electrodeposited nanocrystalline $\mathrm{Ni}$ foils produced by pulse plating onto titanium substrate,

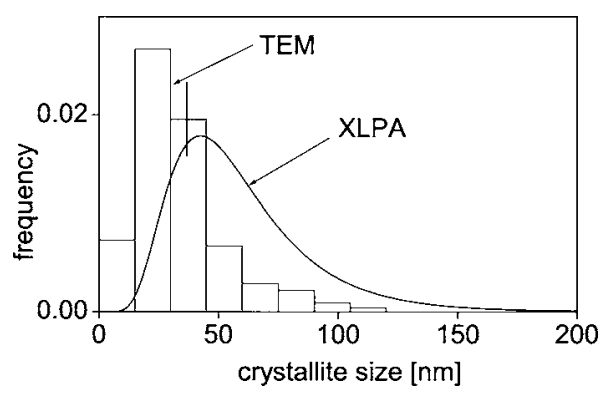

Figure 2. The grain size distribution obtained by TEM (bar diagram), and the crystallite size distribution determined by XLPA (solid line) (the vertical line is an estimated error bar).
XLPA provided $\langle x\rangle_{\text {area }}=12 \mathrm{~nm}$ and $\langle x\rangle_{\mathrm{vol}}=38 \mathrm{~nm}$ for the area- and volume-weighted mean crystallite diameters, respectively (Tóth-Kádár et al., 1987; Bakonyi et al., 1996). Although the TEM micrograph obtained on the same specimen has not been evaluated quantitatively for crystallite or grain size, a good qualitative correlation between the X-ray and TEM results can be observed (Tóth-Kádár et al., 1987; Bakonyi et al., 1996). Similar agreement was found for electrodeposited Ni produced by Zhilyaev and co-workers (Zhilyaev et al., 2003). For this sample $\langle x\rangle_{\text {area }}=24 \mathrm{~nm}$ and $\langle x\rangle_{\mathrm{vol}}=45 \mathrm{~nm}$ from XLPA while TEM experiments result in $35 \mathrm{~nm}$ as the area weighted mean grain size.

Nanocrystalline Pd pallets were prepared by inert-gas condensation and subsequent compaction (Krill and Birringer, 1998). Dark field TEM micrographs were evaluated quantitatively. The $111 / 222$ pair of X-ray diffraction peaks were evaluated by the classical Warren-Averbach method. From the area- and the volume-weighted mean crystallite size values the size distribution function has been determined. A good correlation between the bar-diagram obtained from the TEM micrographs and the size-distribution function provided by XLPA was observed. Similar good correlation was found between the TEM and X-ray size distribution functions for nanocrystalline $\mathrm{Cu}$ prepared by inert-gas condensation and subsequent hot compaction at Argonne National Laboratory (Sanders et al., 1997).

Nanocrystalline $\mathrm{Ni}_{5} \mathrm{Hf}$ particles were produced by careful crystallization from an amorphous precursor (Gubicza et al., 2001). The amorphous ribbons of $3 \mathrm{~mm}$ width and $11 \mu \mathrm{m}$ thickness were produced from a master alloy of $\mathrm{Hf}_{11} \mathrm{Ni}_{89}$ melted and fast quenched by the melt-spinning technique. The measured values of the median and variance obtained from XLPA are: $m=3.3 \mathrm{~nm}$ and $\sigma=0.82$. The arithmetic-, the area-, and the volume-weighted mean crystallite size values calculated from $m$ and $\sigma$ are 5, 17, and $35 \mathrm{~nm}$, respectively. They indicate a wide size distribution in good correlation with TEM observations. From the TEM micrograph the area weighted mean grain size has been determined to be about $10 \mathrm{~nm}$ in relatively good correlation with XLPA results.

\section{B. When X-ray and TEM sizes show discrepancies}

It is a general observation that in plastically deformed bulk metals the grain size determined by TEM is much higher than the crystallite size obtained by XLPA. In the following several examples of this phenomena are discussed.

The microstructure of a ferritic/martensitic steel from the European Fusion Materials Technology Programme (EFMTP) was investigated by TEM by Marmy and coworkers (Marmy et al., 1991). It was found that the strength of the tempered martensite is caused by the carbide precipitates and by the lath structure which is strengthened by a high density of dislocations. After tensile deformation or low cycle fatigue a well-developed dislocation cell structure is formed leaving a small amount of the original dislocation density in the martensite. The TEM micrographs revealed strongly elongated laths of the ferritic/martensitic material in which the laths are subdivided by dislocation cell walls. The dislocation densities and the mean crystallite diameters were determined for the normal state and after fatigue at room 


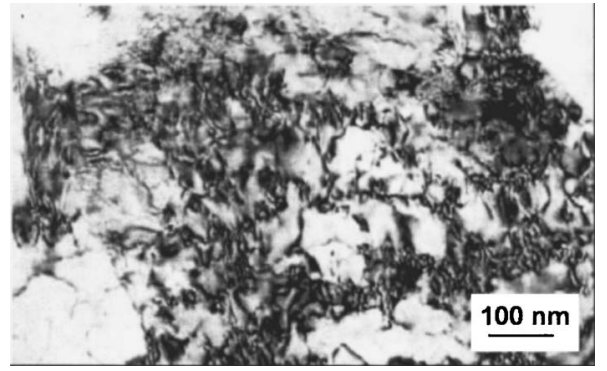

Figure 3. TEM micrograph of a grain containing dislocation cells in ultrafine grained titanium formed by ECAP.

temperature and $250{ }^{\circ} \mathrm{C}$ by XLPA (Marmy et al., 1991). It is found that while the dislocation density increases during fatigue, especially at $250{ }^{\circ} \mathrm{C}$, the mean crystallite size also increases considerably. This indicates that during fatigue, especially at higher temperatures, the dislocation density in the cell walls increases strongly, while simultaneously the dislocation cell size or the subgrain size increases too. The two parameters, i.e., the dislocation density and the areaweighted mean crystallite size, show similar tendency either determined from TEM micrographs or obtained by XLPA, but the grain size determined by TEM was much higher than the area-weighted crystallite size calculated from the X-ray line profiles.

Severe plastic deformation (SPD) methods are effective tools for producing bulk ultrafine grained metals. The two most frequently used SPD procedures are equal channel angular pressing (ECAP) and high pressure torsion (HPT). It has been shown for bulk ultrafine grained $\mathrm{Al}, \mathrm{Al}-3 \% \mathrm{Mg}$, and Ni produced by SPD techniques that the grain size determined by TEM is about four to six times higher than the crystallite size obtained by XLPA (Zhilyaev et al., 2003; Gubicza et al., 2004). When the strain has been increased by the combination of the different deformation procedures (ECAP, HPT, and cold rolling), the ratio of the two sizes was decreased down to about two to three. TEM investigations indicate that the grains in SPD materials are divided into subgrains and/or dislocation cells which are separated from each other by low angle grain boundaries. The crystallite size in SPD metals obtained by X-ray diffraction is equivalent to the mean size of domains which scatter X-rays coherently. Consequently, X-ray diffraction makes a difference between the dislocation cells which are separated from each other by small differences in orientation, typically under $1^{\circ}-2^{\circ}$. The usual TEM investigation (usually performed by visual observation) of SPD metals gives the size of the grains having high angle grain boundaries. As a consequence, the TEM grain size is higher than the dislocation cell size obtained by XLPA. When the different SPD methods are applied after each other to increase the applied strain, the differences in orientation between the dislocation cells or subgrains increase, and the ratio of the TEM grain size and coherently scattering domain size decreases.

Submicron grain-size titanium was produced by ECAP and subsequent cold rolling (Zhu et al., 2003). A detailed TEM study shows that the microstructure is inhomogeneous and shows a hierarchy, i.e., the grains contain subgrains which are further divided into dislocation cells. For example the large grains in Figure 3 consist of dislocation cells. The

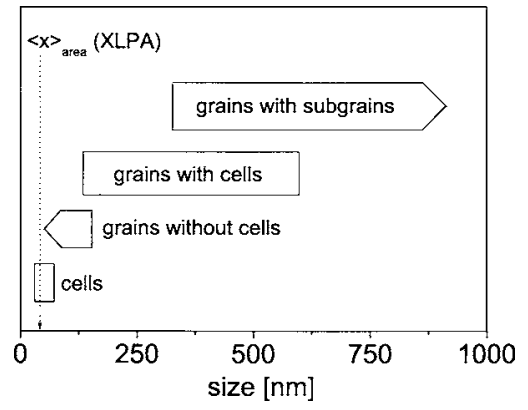

Figure 4. The statistical size ranges of different structural features in ECAP processed titanium.

distribution of grain sizes is broad from less than $100 \mathrm{~nm}$ to over $600 \mathrm{~nm}$. The structure of grains is dependent on their size but the size ranges of grains with different structures are overlapped. Figure 4 shows the statistical size ranges of different structural features. Grains containing subgrains are usually larger than $320 \mathrm{~nm}$. Grains having dislocation cell structure without the intermediate subgrains are in the size range of 130-600 $\mathrm{nm}$. Grains which have no dislocation cells are smaller than $150 \mathrm{~nm}$. The dislocation cells are in the size range of $30-70 \mathrm{~nm}$ and the average cell size is $45 \mathrm{~nm}$. The average grain size observed in TEM is much larger, about $270 \mathrm{~nm}$ (Zhu et al., 2003). The XLPA results in the area-weighted mean crystallite size of $41 \mathrm{~nm}$ which is several times smaller than the grain size obtained by TEM but it is in a relatively good correlation with the TEM cell size (see Figure 4).

A $99.98 \%$ copper specimen was extruded and subsequently deformed by ECAP in a single pass (Ungár et al., 2001; Ribárik et al., 2001). TEM micrographs obtained on this specimen were evaluated in two steps. In a first step the well-defined, large angle grain boundaries were drawn into a contour map. This procedure was carried out on about ten similar micrographs. The linear intersection method was used to produce the bar graph of the distribution of crystallite diameters. It was established that the TEM size distribution gives much larger size values than the X-ray method. The median of the size distribution determined by XLPA was about $60 \mathrm{~nm}$ while that of the grains observed by TEM was about two to three times higher. In a second step typical grains in good contrast orientation were selected and finer contour maps were produced which corresponds to the dislocation cell structure. These contour maps were also evaluated by the linear intersection method and this size distribution was close to that determined from X-rays (Ungár et al., 2001). This indicates that in a plastically deformed bulk metallic specimen the crystallite size and size distribution obtained by the X-ray method are close or almost equal to the dislocation cell size or size distribution.

The above-mentioned examples show that in the case of loose ceramic powders and metallic materials produced by inert-gas condensation or electrodeposition, as long as the grain diameter is within the sensitivity range of X-ray diffraction peak broadening, i.e., smaller than about $1 \mu \mathrm{m}$, TEM or HREM grain sizes are in good agreement with size and size-distribution results provided by XLPA. The grain size of SPD materials determined by TEM is generally several times higher than the crystallite size (or coherently scat- 


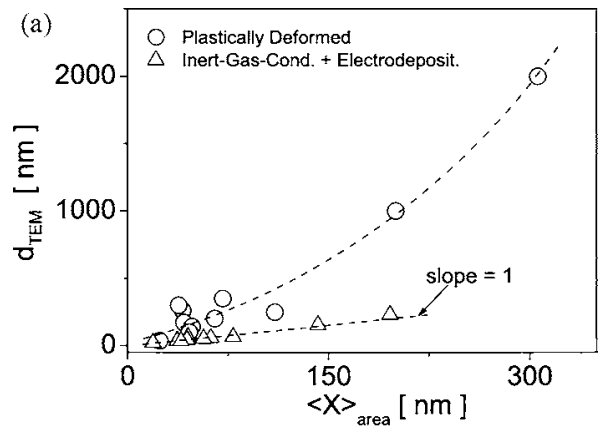

(b)

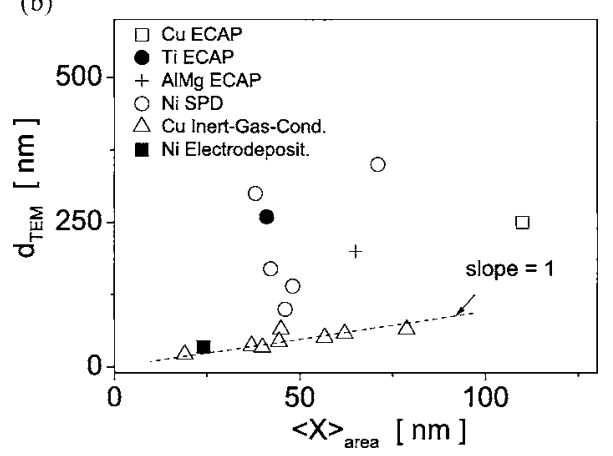

Figure 5 . The grain size determined by TEM $\left(d_{\text {TEM }}\right)$ vs the area-weighted mean crystallite size obtained from XLPA $\left(\langle x\rangle_{\text {area }}\right)$ for plastically deformed metals and for metallic materials produced by inert-gas condensation or electrodeposition (a). The small grain size region of (a) is replotted in (b) where the different materials are indicated by different symbols: open square-Cu deformed by ECAP (Ungár et al., 2001); closed circle-Ti processed by ECAP (Zhu et al., 2003); cross-Al-3\%Mg formed by ECAP (Gubicza et al., 2004); open circle-Ni specimens obtained by different SPD methods (Zhilyaev et al., 2003); open triangle - Cu formed by inertgas condensation (Sanders et al., 1997); closed square-electrodeposited $\mathrm{Ni}$ (Zhilyaev et al., 2003).

tering domain size) obtained by XLPA. This is illustrated in Figure 5(a) where the TEM grain size is plotted versus the crystallite size determined by XLPA for metallic materials. The figure shows that for metals produced by electrodeposition or inert-gas condensation the two sizes are in good agreement while for metallic specimens formed by SPD the grain size is higher than the crystallite size. For better visibility, the small grain size region of Figure 5(a) is replotted in Figure 5(b) where the different materials are indicated by different symbols.

The reason for the difference between the TEM and XLPA sizes for SPD metals originates from the hierarchy of the microstructure. During SPD process the basic mechanisms of the grain refinement are the multiplication of dislocations and the subsequent arrangement into cell boundaries to minimise their strain energy. The dislocation cells have low-angle grain boundaries. As the deformation proceeds the dislocation density in the cell boundaries increases (even up to $10^{17}-10^{18} \mathrm{~m}^{-2}$ ), the thickness of the boundaries decreases, and the difference in orientation between the neighboring cells also increase, i.e., the cell boundaries are transformed into high-angle grain boundaries. At a certain strain the microstructure contains low-angle cell boundaries [or incidental dislocation boundaries (IDBs)] and high-angle grain boundaries [geometrically necessary boundaries (GNBs)] simultaneously (Hughes and Hansen, 2000). The grains confined by high-angle boundaries are subdivided into subgrains and/or

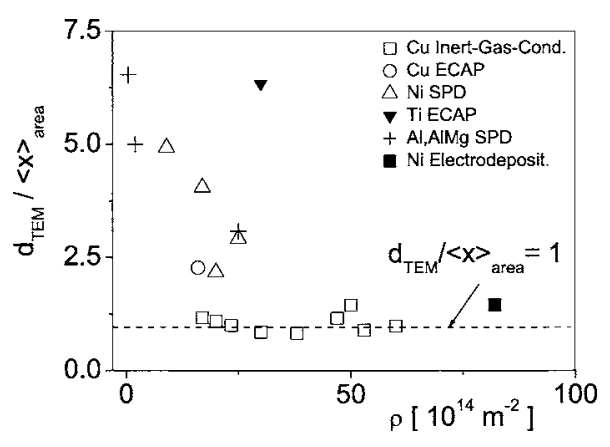

Figure 6 . The ratio of the grain size determined by TEM and the crystallite size obtained by XLPA vs the dislocation density: open square- $\mathrm{Cu}$ formed by inert-gas condensation (Sanders et al., 1997); open circle- $\mathrm{Cu}$ deformed by ECAP (Ungár et al., 2001); open triangle-Ni specimens obtained by different SPD methods (Zhilyaev et al., 2003); closed inverted triangle-Ti processed by ECAP (Zhu et al., 2003); cross-pure Al and Al-3\% Mg formed by ECAP (Gubicza et al., 2004); closed square-electrodeposited Ni (Zhilyaev et al., 2003).

cells. The differences in orientation between cells is low $\left(1^{\circ}-\right.$ $2^{\circ}$ ) therefore there is no measurable contrast difference between them in TEM micrographs, i.e., they can be observed separately only by high-resolution TEM investigations. At the same time there is no coherency between the X-rays scattered from the different cells, therefore X-ray line profile analysis measures the size of these objects. As the strain increases the dislocation density also increases and the lowangle cell boundaries transformed to high-angle boundaries. Consequently, the TEM and XLPA sizes converge with increasing dislocation density as Figure 6 shows for different metals. In this figure the specimens formed by inert-gas condensation or electrodeposition are also plotted. The ratio of the two sizes corresponding to these samples is close to 1 . Although in the case of SPD metals the lower crystallite size is associated with the higher dislocation density, there is no strict correlation between the two quantities obtained by XLPA as shown in Figure 7. The relationship between the dislocation density and the mean crystallite size can be described by power law with different exponents $(n)$ depending on the type of materials (see Figure 7).

In the following section it is demonstrated that during SPD processes a special dislocation structure can develop which does not cause any differences in orientation but it

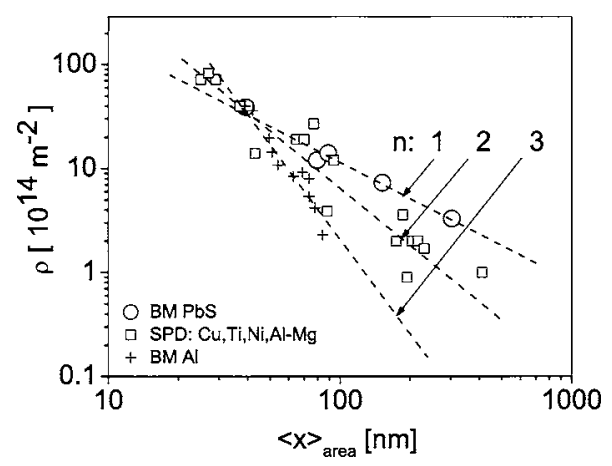

Figure 7. The dislocation density vs the area-weighted mean crystallite size for different series of plastically deformed materials: open circle-ball milled PbS (Ungár et al., 2002); open square-Cu, Ti, Ni, and Al-3\% Mg processed by SPD methods (Ungár et al., 2001; Zhilyaev et al., 2003; Zhu et al., 2003; Gubicza et al., 2004); cross—ball milled Al (Révész et al., 2000). 
results in disappearance of the coherency between the different domains of grains. As a consequence, the smallest object size measured by careful TEM investigations is still much higher than the coherently scattering domain size determined by XLPA.

\section{THE EFFECT OF DIPOLAR DISLOCATION WALLS ON COHERENT SCATTERING}

Dipolar dislocation walls are one of the most common dislocation configurations in plastically deformed crystalline materials (Kuhlmann-Wilsdorf, 2002). They do not cause tilt or twist between the two delineated regions (Wilkens et al., 1987) therefore, it is not trivial whether they break down coherent scattering.

In materials, where deformation proceeds by wavy-glide, TEM observations have shown that dislocations form a cell structure (Mughrabi, 1983). At first, thick and woolly cell walls of high dislocation density surround cell-interior regions with considerably lower dislocation densities. At later stages of deformation cell blocks appear which comprise many dislocation cells being separated by differences in orientation of tilt or twist. With further deformation the cell blocks shrink, the cell walls become thin and often form lamellar structures separated by marked differences in orientation (Gil-Sevillano and Aernoudt, 1987; Hughes and Nix, 1989; Hughes and Hansen, 1993; Kuhlmann-Wilsdorf, 2002). Within the lamellae, however, almost no, or just slightly different orientations between the adjacent subgrains can be observed. A typical TEM micrograph of a copper specimen deformed by a single pass of ECAP at room temperature using a $90^{\circ}$ die is shown in Figure 8(a) (Hellmig et al., 2004). The differences in orientation between adjacent regions have been evaluated quantitatively by TEM investigations. A schematic representation of the measured differences in orientation is shown in Figure 8(b). The black lines correspond to large differences in orientation ranging up to $25^{\circ}$ [see Figure 3(b) in Hellmig et al., 2004]. The gray lines correspond to slightly different orientations ranging from 0.2 to about $8^{\circ}$ [see Figure 3(a) in Hellmig et al., 2004]. The boundaries corresponding to large and slightly different orientations are called geometrically necessary boundaries (GNBs) and incidental dislocation boundaries (IDBs), respectively (Hellmig et al., 2004). The size of subgrains with large and slightly different orientations is about 400 or $200 \mathrm{~nm}$, respectively. The X-ray line profile analysis carried out by the MWP method gives about $70 \mathrm{~nm}$ for the areaweighted mean crystallite size. This shows that the TEM subgrain size is still much larger than the crystallite size obtained by XLPA, even if the objects with small differences in orientation are taken into account. In the following it is shown that dipolar dislocation walls break down coherent scattering despite there being no difference in orientation between the delineated regions. Since dipolar dislocation walls with almost or perfectly zero differences in orientation are a general feature of plastically deformed materials (KuhlmannWilsdorf, 2002), the discrepancy between crystallite size determined by XLPA and TEM is attempted to be explained by the presence of these dipolar dislocation walls.

A schematic dipolar dislocation wall is shown in Figure 9(a). For the sake of simplicity, however, not violating gen-
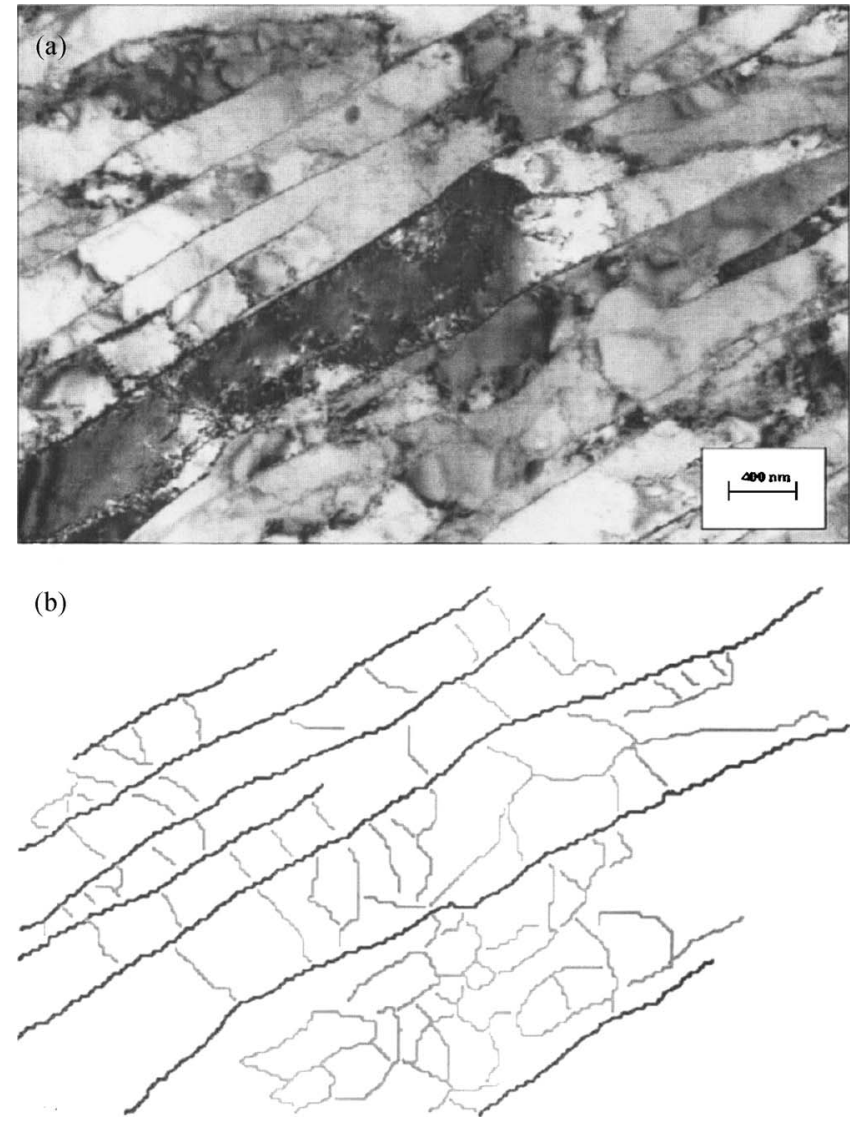

Figure 8. TEM micrograph of a copper specimen deformed by a single pass of ECAP (a). The schematic representation of the measured differences in orientation in (a) is shown in (b). The black lines correspond to large differences in orientation ranging up to $25^{\circ}$ while the grey lines correspond to almost zero or small differences in orientation ranging from $0.2^{\circ}$ to about $8^{\circ}$.

erality, edge dislocations are considered with the Burgers vectors parallel to the $x$ direction and $y$ perpendicular to the dipolar wall. The dislocation dipoles are arranged periodically with the period $s$, and are characterised by the two parameters $\eta$ and $\delta$ [see also in Figure 9(a)]. Denoting the displacement field of a single dislocation by $\underline{u}_{D}(x, y)$, the total displacement field of the dipolar wall is

$$
\underline{u}(x, y)=\sum_{n=-\infty}^{n=\infty}\left[\underline{u}_{D}(x-n s, y-\eta)-\underline{u}_{D}(x-n s-\delta, y)\right],
$$

where $n$ is an integer and $s$ is the periodicity of the dislocations. At $y= \pm \infty$ the two lattices on the two sides of the dipolar wall are shifted with respect to each other by $\underline{t}$ in the $x$ direction:

$$
\underline{t}=\lim _{y \rightarrow \infty} \underline{u}(x, y)-\lim _{y \rightarrow-\infty} \underline{u}(x, y) .
$$

Obviously, $\underline{t}$ is independent either of $\eta$ or of $x$. It can be seen that if $\delta=0$, then $\underline{t}=0$. Let $\underline{u}_{D}(x, y)$ be divided into the topological part, $\underline{u}_{T}(x, y)$, and the rest: $\underline{u}_{P}(x, y)$, where

$$
\underline{u}_{T}(x, y)=\frac{\underline{b}}{2 \pi} \arctan \frac{x}{y},
$$

where $\underline{b}$ is the Burgers vector of the dislocations in the dipolar wall. $\underline{u}_{P}(x, y)$ contains the logarithmic part of the displacement field and is an even function of both $x$ and $y$. 
(a)

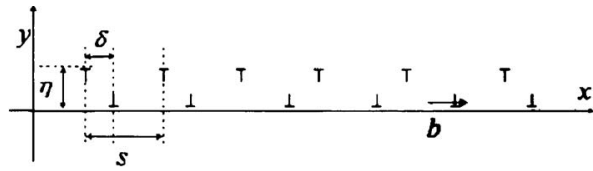

(b)
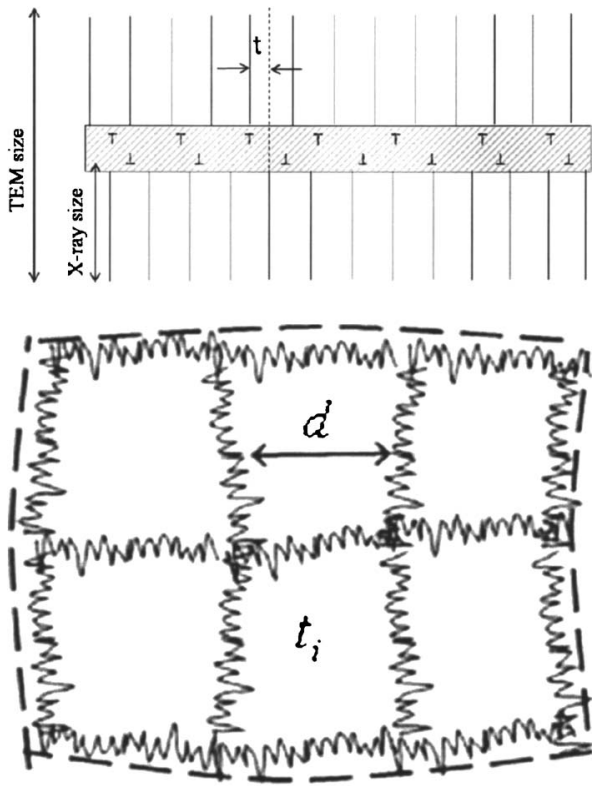

(c)

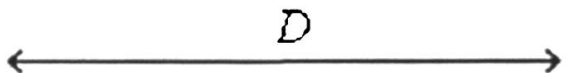

Figure 9. A schematic dipolar dislocation wall (a). The dislocations are arranged periodically with the period $s$, and the width and the thickness of the dipoles is $\eta$ and $\delta$, respectively. The shift, $t$, of the two lattice halves on the two sides of the dipolar wall is shown in (b). A schematic representation of the structure of a grain interior is shown in (c). The randomly hatched regions are for the subgrain boundaries, in the present case they are assumed to be dipolar dislocation walls. The thick dashed lines represent the large angle grain boundaries. $D$ and $d$ are the grain-and subgrain size, respectively. The lattice-shift relative to the adjacent subgrain lattice in the $i$ th subgrain is $\underline{t}_{i}$

Since the limes of $\underline{u}(x, y)$ is singular at $y$ infinity, the derivatives are investigated:

$$
\frac{d \underline{t}}{d \delta}=\lim _{y \rightarrow \infty} \frac{\partial \underline{u}(x, y)}{\partial \delta}-\lim _{y \rightarrow-\infty} \frac{\partial \underline{u}(x, y)}{\partial \delta}
$$

where

$$
\frac{\partial \underline{u}}{\partial \delta}=\frac{\partial}{\partial \delta} \sum_{n=-\infty}^{\infty}\left[\underline{u}_{D}(x-n s, y-\eta)-\underline{u}_{D}(x-n s-\delta, y)\right] .
$$

Since $\underline{u}_{P}$ is an even function, only $\underline{u}_{T}$ will contribute to $\partial \underline{u} / \partial \delta$ :

$$
\frac{\partial \underline{u}}{\partial \delta}=\frac{\partial}{\partial \delta} \sum_{n=-\infty}^{\infty}\left[-\underline{u}_{T}(x-n s-\delta, y)\right]=\sum_{n-\infty}^{\infty} \frac{\partial \underline{u}_{T}(x-n s-\delta)}{\partial x}
$$

and

$$
\frac{\partial \underline{u}}{\partial \delta}=\frac{\underline{b}}{2 \pi} \sum_{n=-\infty}^{\infty} \frac{y}{(x-n s-\delta)^{2}+y^{2}} .
$$

Based on Poisson's rule the summation in Eq. (8) can be replaced by the integral:

$$
\frac{\partial \underline{u}}{\partial \delta}=\frac{\underline{b}}{2 \pi} \int_{-\infty}^{\infty} \frac{y}{z^{2}+y^{2}} \frac{d z}{s}
$$

where the $z=x-n s-\delta$ replacement has been used. The integral is equal to $\pi / 2 \operatorname{sign}(y)$, thus

$$
\frac{\partial \underline{u}}{\partial \delta}=\frac{\underline{b}}{2 s} \operatorname{sign}(y), \quad \frac{d \underline{t}}{d \delta}=\frac{\underline{b}}{s} .
$$

The shift, $\underline{t}$, of the two lattice halves on the two sides of the dipolar wall is $\underline{t}=(\underline{b} / s) \delta$ and is shown schematically in Figure 9(b). Due to lattice periodicity, the maximum value of $t$ is $\underline{t}_{\max }= \pm \underline{b} / 2$.

Now the scattering of subgrains is calculated where the subgrain boundaries are dipolar dislocation walls and the subgrains are embedded in a grain bordered by large angle grain boundaries, as shown schematically in Figure 9(c). The randomly hatched regions are for the subgrain boundaries; in the present case they are assumed to be dipolar dislocation walls. The thick dashed lines represent the large angle grain boundaries. $D$ and $d$ are the grain and subgrain size, respectively. The lattice shift relative to the adjacent subgrain lattice in the $i$ th subgrain is $\underline{t}_{i}$. Denote the structure factor of the $i$ th subgrain by $S_{i}$, then the size broadened line profile of the whole grain is

$$
|S|^{2}=\left|\sum_{i} e^{2 \pi i g t_{i}} S_{i}\right|^{2}=\sum_{i, j} e^{2 \pi i g\left(t_{i}-t_{j}\right)} S_{i} S_{j}^{*},
$$

where $g$ is the diffraction vector and only the shape of the line profile is considered. The double sum can be written as

$$
|S|^{2}=\sum_{i}\left|S_{i}\right|^{2}+\sum_{i \neq j} e^{2 \pi i \underline{g}\left(t_{i}-t_{j}\right)} S_{i} S_{j}^{*} .
$$

Since $\underline{t}_{i}$ are random, the second term on the right-hand side becomes negligible, and

$$
|S|^{2}=\sum_{i}\left|S_{i}\right|^{2} .
$$

Equation (13) means that the subgrains scatter out of phase, therefore their intensities add up. In other words, the line profile of the whole grain will be the sum of the line profiles of the subgrains. As a result, size broadening will be determined by the size broadening corresponding to the subgrains, instead of corresponding to the grains. The physical meaning of Eqs. (12) and (13) can also be interpreted as follows: size broadening will be determined by the average subgrain-size since the scattering of each subgrain is shifted by a random phase-factor.

The determination of subgrain size or subgrain sizedistribution from TEM micrographs is probably an almost impossible task, especially when the dislocation density is high and the subgrain size small. The difficulties encountered when attempting this aim are illustrated by the micrograph and the corresponding schematic line-graph of Figures 3(a) and 3(b) in Hellmig et al. (2004) and shown here as Figures 8 (a) and 8(b), respectively. The careful investigation of the 


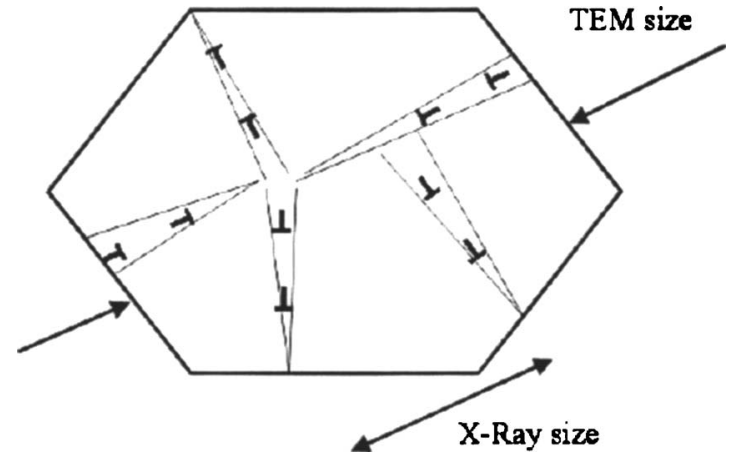

Figure 10. The schematic picture of subgrain or cell structure where dislocations constitute the boundaries of subgrains or cells with slightly different orientations. The figure is similar in its meaning to the schematic illustration in Figure 15.6 of Bolmaro et al. (2004).

micrograph in Figure 8(a) shows several details which are not indicated in the corresponding schematic line-graph in Figure 8(b). It is quite evident that a quantitative evaluation of a TEM micrograph for the sake of determining subgrain size distribution becomes rather subjective, especially when the finer details are attempted to be obtained. The X-ray method might be considered as somewhat more objective, at least for the determination of subgrain/cell size and sizedistribution.

\section{DISCUSSION AND CONCLUSIONS}

The scrutiny of the correlation between crystallite size determination either by XLPA or by TEM has shown that the $\mathrm{X}$-ray size is usually either equal to or smaller than the TEM size. In those cases when the crystallites or particles are delineated by well-defined boundaries, as in the case of metallic samples produced by the method of inert gas condensation (Sanders et al., 1997), or in the case of loose particles of ceramic materials (Louër et al., 1983; Gubicza et al., 2000a; Scardi and Leoni, 2002), the X-ray and TEM data are in good correlation. In the case of bulk ultrafine grained materials formed by SPD methods, however, the X-ray size values are usually smaller than the TEM data, cf. Zhilyaev et al., 2003; Gubicza et al., 2004; Zehetbauer et al., 2004. The arrangement of dislocations into small-angle grain boundaries provides a simple and straightforward model for subgrain/cell structure where the TEM grain size is obviously larger than the X-ray subgrain/cell size, as shown schematically in Figure 15.6 of Bolmaro et al. (2004) and in Figure 10 here. The thorough and systematic measurements of differences in orientation between adjacent subgrains in an ECAP deformed copper specimen (Hellmig et al., 2004) have shown, however, that considerable fractions of subgrains are not separated by significant differences in orientation. These TEM investigations indicate that the small angle grain boundary model of subgrain boundaries is definitely not sufficient to explain the apparent discrepancy between TEM and X-ray size values. In the present work it has been shown that when dislocations are arranged in dipolar dislocation-wall configurations the two crystal-halfs on either side of such a wall are shifted with respect to each other parallel to the direction of their Burgers vectors, where this shift varies randomly between zero and $\underline{b} / 2$. This random spatial shift causes a random phase shift of the X-rays scattered by the adjacent subgrains. As a result, the intensities of the scattering from adjacent subgrains will be summed up and the line broadening will be determined by the average subgrain size. The two models, i.e., the small-angle grainboundary model and the dipolar dislocation-wall model of subgrain boundaries, provide together a physically wellestablished basis for the assumption that size and size distributions determined by X-ray line profile analysis correspond to subgrains or dislocation cells. If, however, the subgrains/ cells and the grains are identical, as might happen in many cases, then the TEM and X-ray size data can be identical. Finally it is noted that neither dipolar dislocation walls nor small angle grain boundaries are so perfect arrays of dislocations as depicted in the schematic drawings in Figures 9 and 10 , respectively. The arrays will not be perfectly regular, and the dislocations may be of different type and/or orientation and/or sign. For example there may be some dipoles within the small angle grain boundaries, or the dipolar walls may be not straight or flat, and they may also contain different types of dislocations or more dislocations of one sign. The schematic pictures in Figures 9 and 10 intend only to show the net structure and behavior of two different types of boundaries.

\section{ACKNOWLEDGMENT}

This work was supported by the Hungarian Scientific Research Fund, OTKA, Grant Nos. F-047057, T-038048, and T-042714.

Audebrand, N., Raite, S., and Louër, D. (2003). "The layer crystal structure of $\left[\mathrm{In}_{2}\left(\mathrm{C}_{2} \mathrm{O}_{4}\right)_{3}\left(\mathrm{H}_{2} \mathrm{O}\right)_{3}\right] \cdot 7 \mathrm{H}_{2} \mathrm{O}$ and microstructure of nanocrystalline $\mathrm{In}_{2} \mathrm{O}_{3}$ obtained from thermal decomposition," Solid State Sci. 5, 783794.

Bakonyi, I., Tóth-Kádár, E., Pogány, L., Cziráki, A., Geröcs, I., VargaJosepovits, K., Arnold, B., and Wetzig, K. (1996). "Preparation and characterization of dc-plated nanocrystalline nickel electrodeposits," Surf. Coat. Technol. 78, 124-136.

Balzar, D., Audebrand, N., Daymond, M. R., Fitch, A., Hewat, A., Langford, J. I., Le Bail, A., Louër, D., Masson, O., McCowan, C. N., Popa, N. C., Stephens, P. W., and Toby, B. H. (2004). "Size-strain linebroadening analysis of the ceria round-robin sample," J. Appl. Crystallogr. 37, 911-924.

Bertaut, E. F. (1950). "Raies de Debye-Scherrer et repartition des dimensions des domaines de Bragg dans les poudres polycristallines," Acta Crystallogr. 3, 14-18.

Bolmaro, R. E., Brokmeier, H. G., Signorelli, J. W., Fourtz, A., and Bertinetti, M. A. (2004). "Interaction between phases in Co-deforming two-phase materials: The role of dislocation arrangements," in Diffraction Analysis of the Microstructure of Materials, edited by E. J. Mittemeijer and P. Scardi (Springer, Berlin), $391 \mathrm{pp}$.

Boulle, A., Legrand, C., Guinebretière, R., Mercurio, J. P., and Dauger, A. (2001). "Planar faults in layered bi-containing perovskites studied by X-ray diffraction line profile analysis," J. Appl. Crystallogr. 34, 699703.

Cheary, R. W., Dooryhee, E., Lynch, P., Armstrong, N., and Dligatch, S. (2000). "X-ray diffraction line broadening from thermally deposited gold films," J. Appl. Crystallogr. 33, 1271-1283.

Dinnebier, R. E., Von Dreele, R., Stephens, P. W., Jelonek, S., and Sieler, J. (1999). "Structure of sodium para-hydroxybenzoate $\mathrm{NaO} 2 \mathrm{C}-\mathrm{C} 6 \mathrm{H} 4 \mathrm{OH}$ by powder diffraction: application of a phenomenological model of anisotropic peak width,” J. Appl. Crystallogr. 32, 761-769.

Estevez-Rams, E., Leoni, M., Scardi, P., Aragon-Fernandez, B., and Fuess, H. (2003). "On the powder diffraction pattern of crystals with stacking faults," Philos. Mag. 83, 4045-4057.

Gaál, I. (1984). Proceedings of the Fifth Riso International Symposium on 
Metallurgy and Material Science, edited by N. H. Andersen et al., Riso National Laboratory, Roskilde, Denmark, 249 pp.

Gil Sevillano, J. and Aernoudt, E. (1987). "Low energy dislocation structures in highly deformed materials," Mater. Sci. Eng. 86, 35-51.

Groma, I. (1998). "X-ray line broadening due to an inhomogeneous dislocation distribution," Phys. Rev. B 57, 7535-7542.

Groma, I., Ungár, T., and Wilkens, M. (1988). "Asymmetric X-ray line broadening of plastically deformed crystals. 1. Theory," J. Appl. Crystallogr. 21, 47-53.

Gubicza, J., Chinh, N. Q., Horita, Z., and Langdon, T. G. (2004). "Effect of $\mathrm{Mg}$ addition on microstructure and mechanical properties of aluminum," Mater. Sci. Eng., A 387-389, 55-59.

Gubicza, J., Ribárik, G., Bakonyi, I., and Ungár, T. (2001). “Crystallite-size distribution and dislocation structure in nanocrystalline HfNi5 determined by X-ray diffraction profile analysis," J. Nanosci. Nanotechnol. 1, 343-348.

Gubicza, J., Szépvölgyi, J., Mohai, I., Ribárik, G., and Ungár, T. (2000a). "The effect of heat-treatment on the grain-size of nanodisperse plasmathermal silicon nitride powder," J. Mater. Sci. 35, 3711-3717.

Gubicza, J., Szépvölgyi, J., Mohai, I., Zsoldos, L., and Ungár, T. (2000b). "Particle size distribution and the dislocation density determined by high resolution X-ray diffraction in nanocrystalline silicon nitride powders," Mater. Sci. Eng. A 280, 263-269.

Hellmig, R. J., Baik, S. C., Bowen, J. R., Estrin, Y., Juul Jensen, D., Kim, H. S., and Seo, M. H. (2004). "Evolution of mechanical and microstructural properties of ECAP deformed copper," in Proceedings of the Second International Conference on Nanomaterials by Severe Plastic Deformation: Fundamentals-Processing-Applications, Wien, Austria, 9-13 December 2002, edited by M. J. Zehetbauer and R. Z. Valiev (Wiley VCH, Weinheim), $420 \mathrm{pp}$.

Hinds, W. C. (1982). Aerosol Technology: Properties, Behavior and Measurement of Airbone Particles (Wiley, New York).

Hughes, D. A. and Hansen, N. (1993). "Microstructural evolution in nickel during rolling from intermediate to large strains," Metall. Trans. A 24, 2021-2037.

Hughes, D. A. and Hansen, N. (2000). "Microstructure and strength of nickel at large strains," Acta Mater. 48, 2985-3004.

Hughes, D. A. and Nix, W. D. (1989). "Strain hardening and substructural evolution in Ni-Co solid solutions at large strains," Mater. Sci. Eng., A 122, 153-172.

Ida, T., Shimazaki, S., Hibino, H., and Toraya, H. (2003). "Diffraction peak profiles from spherical crystallites with lognormal size distribution," J. Appl. Crystallogr. 36, 1107-1115.

Krill, C. E. and Birringer, R. (1998). "Estimating grain-size distributions in nanocrystalline materials from X-ray diffraction profile analysis," Philos. Mag. A 77, 621-640.

Krivoglaz, M. A. (1996). X-ray and Neutron Diffraction in Nonideal Crystals (Springer, Berlin).

Kuhlmann-Wilsdorf, D. (2002). "The LES theory of solid plasticity," in Dislocations in Solids, edited by F. R. N. Nabarro and M. S. Duesbery (Elsevier Science, Amsterdam), 211 pp.

Langford, J. I., Boultif, A., Auffrédic, J. P., and Louër, D. (1993). "The use of pattern decomposition to study the combined X-ray diffraction effects of crystallite size and stacking faults in ex-oxalate zinc oxide," J. Appl. Crystallogr. 26, 22-33.

Langford, J. I. and Louër, D. (1996). "Powder diffraction,” Rep. Prog. Phys. 59, 131-234.

Langford, J. I., Louër, D., and Scardi, P. (2000). "Effect of a crystallite size distribution on X-ray diffraction line profiles and whole-powder-pattern fitting," J. Appl. Crystallogr. 33, 964-974.

Le Bail, A. and Louër, D. (1978). "Smoothing and validity of crystallite-size distributions from X-ray line-profile analysis," J. Appl. Crystallogr. 11, $50-55$.

Leoni, M. and Scardi, P. (2004). "Nanocrystalline domain size distributions from powder diffraction data," J. Appl. Crystallogr. 37, 629-634.

Levine, L. E. and Thomson, R. (1997). "X-ray scattering by dislocations in crystals. General theory and application to screw dislocations," Acta Crystallogr., Sect. A: Found. Crystallogr. 53, 590-602.

Louër, D., Auffrédic, J. P., Langford, J. I., Ciosmak, D., and Niepce, J. C. (1983). "A precise determination of the shape, size and distribution of size of crystallites in zinc oxide by X-ray line-broadening analysis," J. Appl. Crystallogr. 16, 183-191.

Macherauch, E. (1980). "State-of-the-art and prospects of the X-ray stress analysis. 1," Metall 34, 443-452.

Marmy, P., Yuzhen, R., and Victoria, M. J. (1991). "The tensile and fatigue properties of type-1.4914 ferritic steel for fusion reactor applications," J. Nucl. Mater. 179, 697-701.

Mughrabi, H. (1983). "Dislocation wall and cell structures and long-range internal-stresses in deformed metal crystals," Acta Metall. 31, 13671379.

Mughrabi, H., Ungár, T., Kienle, W., and Wilkens, M. (1986). "Long-range internal-stresses and asymmetric X-ray line broadening in tensile deformed [001]-oriented copper single crystals," Philos. Mag. A 53, 793813.

Noyan, I. C. and Cohen, J. B. (1987). Residual Stress (Springer, New York).

Révész, A., Lendvai, J., and Ungár, T. (2000). "Melting point depression and microstructure in ball-milled nanocrystalline aluminium powders," Mater. Sci. Forum 343-3, 326-331.

Ribárik, G., Ungár, T., and Gubicza, J. (2001). "MWP-fit: A program for multiple whole profile fitting of diffraction profiles by ab-initio theoretical functions," J. Appl. Crystallogr. 34, 669-676.

Sanders, P. G., Fougere, G. E., Thompson, L. J., Eastman, J. A., and Weertman, J. R. (1997). "Improvements in the synthesis and compaction of nanocrystalline materials," Nanostruct. Mater. 8, 243-252.

Scardi, P. and Leoni, M. (1999). "Fourier modelling of the anisotropic line broadening of X-ray diffraction profiles due to line and plane lattice defects," J. Appl. Crystallogr. 32, 671-682.

Scardi, P. and Leoni, M. (2002). "Whole powder pattern modelling," Acta Crystallogr., Sect. A: Found. Crystallogr. 58, 190-200.

Scardi, P., Leoni, M., and Delhez, R. (2004). "Line broadening analysis using integral breadth methods: A critical review," J. Appl. Crystallogr. 37, 381-390.

Stephens, P. W. (1999). "Phenomenological model of anisotropic peak broadening in powder diffraction," J. Appl. Crystallogr. 32, 281-288.

Terwilliger, Ch. D. and Chiang, Y. M. (1995). "Size dependent solute segregation and total solubility in ultrafine polycrystals-Ca in $\mathrm{TiO}_{2}$," Acta Metall. Mater. 43, 319-328.

Tóth-Kádár, E., Bakonyi, I., Sólyom, A., Hering, J., Konczos, G., and Pavlyák, F. (1987). "Preparation and characterization of electrodeposited amorphous Ni-P alloys," Surf. Coat. Technol. 31, 31-43.

Treacy, M. M. J., Newsam, J. M., and Deem, M. W. (1991). “A general recursion method for calculating diffracted intensities from crystals containing planar faults," Proc. R. Soc. London, Ser. A 433, 499-520.

Ungár, T. and Borbély, A. (1996). "The effect of dislocation contrast on X-ray line broadening: A new approach to line profile analysis," Appl. Phys. Lett. 69, 3173-3175.

Ungár, T., Borbély, A., Goren-Muginstein, G. R., Berger, S., and Rosen, A. R. (1999). "Particle-size, size distribution and dislocations in nanocrystalline tungsten-carbide," Nanostruct. Mater. 11, 103-113.

Ungár, T., Gubicza, J., Ribárik, G., and Borbély, A. (2001). “Crystallite size distribution and dislocation structure determined by diffraction profile analysis: Principles and practical application to cubic and hexagonal crystals,” J. Appl. Crystallogr. 34, 298-310.

Ungár, T., Martinetto, P., Ribárik, G., Dooryhee, E., Walter, P., and Anne, M. (2002). "Revealing the powdering methods of black makeup in Ancient Egypt by fitting microstructure based Fourier coefficients to the whole X-ray diffraction profiles of galena," J. Appl. Phys. 91, 24552465.

Ungár, T. and Tichy, G. (1999). "The effect of dislocation contrast on X-ray line profiles in untextured polycrystals," Phys. Status Solidi A 171, 425434.

Ustinov, A. I., Olikhovska, L. O., Budarina, N. M., and Bernard, F. (2004). "Line profile fitting: The case of fcc crystals containing stacking faults," in Diffraction Analysis of the Microstructure of Materials, edited by E. J. Mittemeijer and P. Scardi (Springer, Berlin), 309 pp.

Valiev, R. Z., Kozlov, E. V., Ivanov, Yu. F., Lian, J., Nazarov, A. A., and Baudelet, B. (1994). "Deformation behavior of ultra-fine grained copper," Acta Metall. Mater. 42, 2467-2476.

van Berkum, J. G. M., Vermuelen, A. C., Delhez, R., de Keijser, Th. H., and Mittemeijer, E. J. (1994). "Applicabilities of the Warren-Averbach analysis and an alternative analysis for separation of size and strain broadening," J. Appl. Crystallogr. 27, 345-357.

Warren, B. E. (1990). X-ray Diffraction (Dover, New York).

Wilkens, M. (1970). Fundamental Aspects of Dislocation Theory (National Bureau of Standards Special Publication, Washington, DC.) Vol. II, No. 317, 1195 pp.

Wilkens, M., Ungár, T., and Mughrabi, H. (1987). "X-ray rocking curve broadening of tensile deformed [001]-oriented copper single crystals," Phys. Status Solidi A 104, 157-170.

Zehetbauer, M. J., Kohout, J., Schafler, E., Sachslehner, F., and Dubravina, 
A. (2004). "Plastic deformation of nickel under high hydrostatic pressure," J. Alloys Compd. 378, 329-334.

Zhilyaev, A. P., Gubicza, J., Nurislamova, G., Révész, Á, Suriñach, S., Baró, M. D., and Ungár, T. (2003). "Microstructural Characterization of
Ultrafine-Grained Nickel,” Phys. Status Solidi A 198, 263-271.

Zhu, Y. T., Huang, J. Y., Gubicza, J., Ungár, T., Wang, Y. M., Ma, E., and Valiev, R. Z. (2003). "Nanostructures in Ti processed by severe plastic deformation,” J. Mater. Res. 18, 1908-1917. 